\title{
Effect of Electrolytic Conditions on Electrodeposition of Manganese in NaCl-KCl Melt
}

\author{
Guolong Liu ${ }^{1,2}$, Wei Liu ${ }^{1,2}$, Qian Kou ${ }^{1,2}$, Saijun Xiao ${ }^{1,2, *}$ \\ ${ }^{1}$ School of Metallurgy Engineering, Anhui University of Technology, Maanshan, Anhui, China, \\ 243002; \\ ${ }^{2}$ Key Laboratory of Metallurgical Emission Reduction \& Resources Recycling, Anhui University of \\ Technology, Maanshan, Anhui, China, 243002 \\ *E-mail: xiaosaijunzj@yahoo.com
}

doi: $10.20964 / 2018.03 .74$

Received: 15 November 2017 / Accepted: 14 January 2018 / Published: 5 February 2018

\begin{abstract}
In this paper, molten $\mathrm{NaCl}-\mathrm{KCl}-\mathrm{MnCl}_{2}$ mixture salts were used as electrolyte, tungsten as the cathode and graphite as the anode to explore the influence of different current density, electrolysis temperature and electrolysis time on current efficiency and microstructure of manganese deposits. The morphology of products were examined by scanning electron microscopy. The results demonstrated that the current efficiency and morphology of deposited manganese varied with electrodeposition time, operating temperature and current density. The optimized conditions for the highest current efficiency (98\%) were obtained at the temperature of $710^{\circ} \mathrm{C}$, with the electrodeposition time for $7 \mathrm{~h}$ and the operating current density of $300 \mathrm{~mA} \cdot \mathrm{cm}^{-2}$, respectively.
\end{abstract}

Keywords: Manganese, Electrodeposition, Molten salts, Current efficiency, Morphology

\section{FULL TEXT}

(C) 2018 The Authors. Published by ESG (www.electrochemsci.org). This article is an open access article distributed under the terms and conditions of the Creative Commons Attribution license (http://creativecommons.org/licenses/by/4.0/). 